\title{
ANALYSIS OF ELEMENT SHAPE IN THE DESIGN FOR MULTI-BAND APPLICATIONS
}

\author{
Pidugu Prasad ${ }^{1}$, D Vakula ${ }^{2}$ \\ ${ }^{I}$ M.Tech, Dept. of Electronics and Communication Engineering, NIT Warangal, A.P, India \\ ${ }^{2}$ Assistant Professor, Dept. of Electronics and Communication Engineering, NIT Warangal, A.P, India
}

\begin{abstract}
A novel compact multi-band microstrip antenna is proposed in this paper. The antenna structure is made to resonate at multiple frequencies by introducing two small rectangular strips attached vertically at the edge of a conventional rectangular patch antenna. The designed antenna resonates at $S$ and $C$ bands. The final optimized dimensions of the basic rectangular patch antenna are $40 \times 15 \mathrm{~mm}$ and two rectangular strip lines are spaced at $2.5 \mathrm{~mm}$ with different dimensions. The simulated antenna shows that the return loss of the proposed antenna at resonant modes are lower than $-10 \mathrm{~dB}$. For multi-band applications, the simulation results provide good performance in term of return loss as well as radiation pattern.
\end{abstract}

Keywords: Multi-band, radiation pattern, return loss, Wi-Fi

\section{INTRODUCTION}

Recent advancements in the field of wireless communication systems require a compact multi- band antenna that supports diverse applications at different frequencies. The study of multi-band antennas is crucial owing to its increasing demand in the sophisticated systems. Many techniques have been proposed to relax the system burdens. By miniaturization of patch antenna size will open up ways of solving problems for mobile communications. However, conventional ways of size reduction in patch antenna are shorting post, slots etc.

Antenna optimization for compact size and achieving multiband using coplanar waveguide feeding technique is investigated by Jagath K. H. Gamage1 et al [1] for WLAN applications. Antenna which consists of a square radiating stub and a ground plane with a pair of L-shaped parasitic structures and an inverted T-shaped strips is suggested for multi-band operation [2]. Here, the L and inverted T-shaped strips are responsible for multi-band radiation. A rectangular radiating patch with symmetrical $\mathrm{L}$ and $\mathrm{U}$-shaped slots is proposed for multi-band operation [3] at WLAN / WiMAX applications. For all these antennas [1-3] resonant frequencies of multi-band are controlled by the dimensions of the inserted strips. Single feed stacked patch antenna for triple band operation is presented by O. P. Falade et al [4]. However, fabrication complexity increases with stacked layers. The multi-band using fractals self-affine property is thoroughly investigated by Sachindra et al [5]. By replacing one of the radiating edge of the rectangular patch with Eshaped fractal and a simple probe feed, multi-band operation is achieved [6]. By cutting U-slots on the patch and feeding with L-probe, dual and triple band antenna is designed. The number of resonance bands are equivalent to the number of U-slots inserted on the patch [7].
Microstrip antennas perform multiple functions with the use of a single antenna aperture, thus increasing the antenna efficiency. The proposed antenna has been designed to operate at dual and triple bands. The presented antenna operates at the resonant frequencies of $2.4 \mathrm{GHz}, 3.8 \mathrm{GHz}$, 4.7 GHz, 4.8 GHz, 5.1, 5.8 GHz, 6.5 GHz, and 7.4 GHz is useful for Wi-Fi, WLAN, Hiperlan, WiMAX applications.

\section{THE RECTANGULAR SHAPED PATCH} ANTENNA DESIGN

The geometry and configuration of the multi-frequency planar antenna is illustrated in Fig. 1. Initially a single rectangular patch without strip lines is designed to resonate at a frequency of $2.45 \mathrm{GHz}$. After that, two strip lines are added and the patch resonates at triple-band. Here, for parametric study dimensions of the two strip lines are used. The position of the probe feed is optimized at different positions for all patches for better return loss.

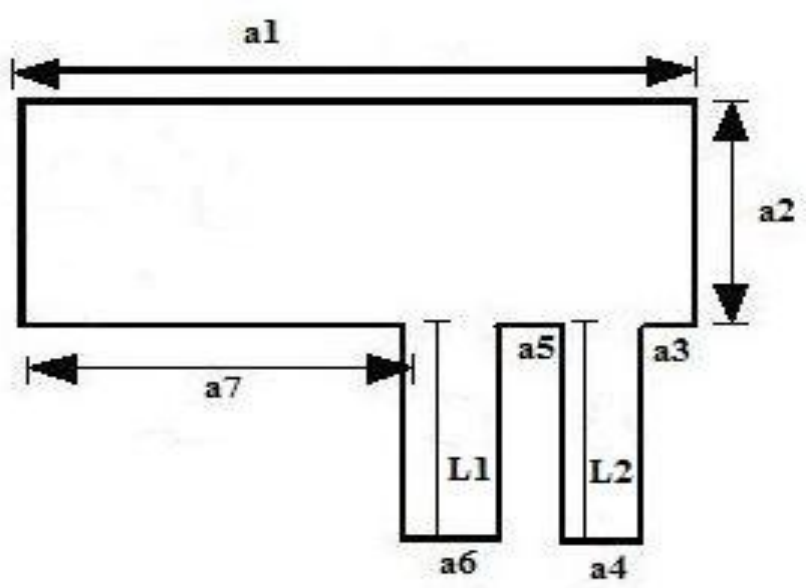

Fig -1 Geometry of the proposed rectangular patch antenna 
Table-1 Dimensions of the Patch antenna.

\begin{tabular}{|l|l|}
\hline Parameter & Values ( mm ) \\
\hline a1 & 40 \\
\hline a2 & 15 \\
\hline a3 & 2.5 \\
\hline a4 & 5 \\
\hline a5 & 2.5 \\
\hline a6 & 5 \\
\hline a7 & 25 \\
\hline
\end{tabular}

The dimensions of the antennas are tabulated in Table 1.

\section{Design Parameters:}

The length and width of the basic patch according to the desired frequency are as follows.

Width of the patch $(\mathrm{W})$ :

$$
W=\frac{c}{2 f_{0}} \sqrt{\frac{2}{\varepsilon_{r}+1}}
$$

Length $(\mathrm{L})$ is given by,

$$
L=\frac{\lambda_{0}}{2 \sqrt{\varepsilon_{\text {reff }}}}-2 \Delta L
$$

Where,

$$
\begin{gathered}
\Delta L=0.412 h \frac{\left(\varepsilon_{\text {eff }}+0.3\right)\left(\frac{W}{h}+0.262\right)}{\left(\varepsilon_{\text {eff }}-0.258\right)\left(\frac{W}{h}+0.813\right)} \\
\varepsilon_{r e f f}=\frac{\varepsilon_{r}+1}{2}+\frac{\varepsilon_{r}-1}{2}\left[1+\frac{12 h}{W}\right]^{-1 / 2}
\end{gathered}
$$

The resonant frequency occurs at multiple bands by varying the approximate lengths of the strip line and width value for the strip is $5 \mathrm{~mm}$. The position of the probe feed is optimized for four different patches.

\section{SIMULATION RESULTS}

RT/Duroid 5880 planar substrate with a $1.57 \mathrm{~mm}$ thickness is used. A standard $50 \Omega$ microstrip probe fed is used to excite the multiple resonant bands, with good matching. The feeding point is set up at the optimized point from the ground plane.
The parameters values are:

1. Dielectric constant $\left(\varepsilon_{r}\right)=2.2$.

2. Center Frequency (fo) $=2.45 \mathrm{GHz}$

3. Substrate Height $(\mathrm{h})=1.57 \mathrm{~mm}$

Multi-band resonant frequencies are observed in the simulated return loss curve due to the increase of electrical length of the patch.

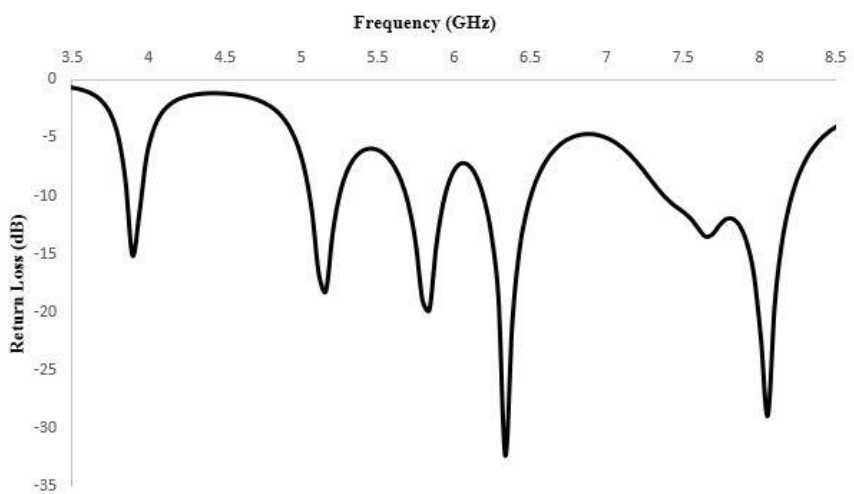

\begin{tabular}{|c|c|c|c|}
\hline $\begin{array}{l}\text { Strip } \\
\text { Lines } \\
\text { Length } \\
(\mathrm{mm})\end{array}$ & $\begin{array}{l}\text { Freq } \\
\text { (GHz) }\end{array}$ & $\begin{array}{l}\text { RL } \\
(\mathbf{d B})\end{array}$ & $\begin{array}{l}\text { 10 dB Impedance } \\
\text { BW } \\
(\%)\end{array}$ \\
\hline \multirow{4}{*}{$\begin{array}{l}\text { Patch 1 } \\
\mathrm{L} 1=29.75 \\
\mathrm{~L} 2=1.25\end{array}$} & 3.8 & -15 & 2.5 \\
\hline & 5.1 & -18.2 & 4.87 \\
\hline & 5.8 & -19 & 4.46 \\
\hline & 6.3 & -32.34 & 4.57 \\
\hline \multirow{2}{*}{$\begin{array}{l}\text { Patch } 2 \\
\mathrm{~L} 1=10 \\
\mathrm{~L} 2=10\end{array}$} & 5.3 & -19.5 & 2.8 \\
\hline & 7.6 & -15.6 & 3.9 \\
\hline \multirow{2}{*}{$\begin{array}{l}\text { Patch 3 } \\
\text { L5 }=6.75 \\
\text { L6 }=2.75\end{array}$} & 2.4 & -40.7 & 2.12 \\
\hline & 4.7 & -11.7 & 2.5 \\
\hline \multirow{3}{*}{$\begin{array}{l}\text { Patch } 4 \\
\text { L7 }=4.75 \\
\text { L8 }=4.75\end{array}$} & 4.8 & -26.6 & 3.25 \\
\hline & 6.5 & -22.9 & 3.87 \\
\hline & 7.4 & -19.86 & 4.2 \\
\hline
\end{tabular}

Fig-2 Return Loss of Patch 1

Table-2 Dimensions of the strip lines with corresponding RL and $10 \mathrm{~dB}$ Impedence BW (\%) results.

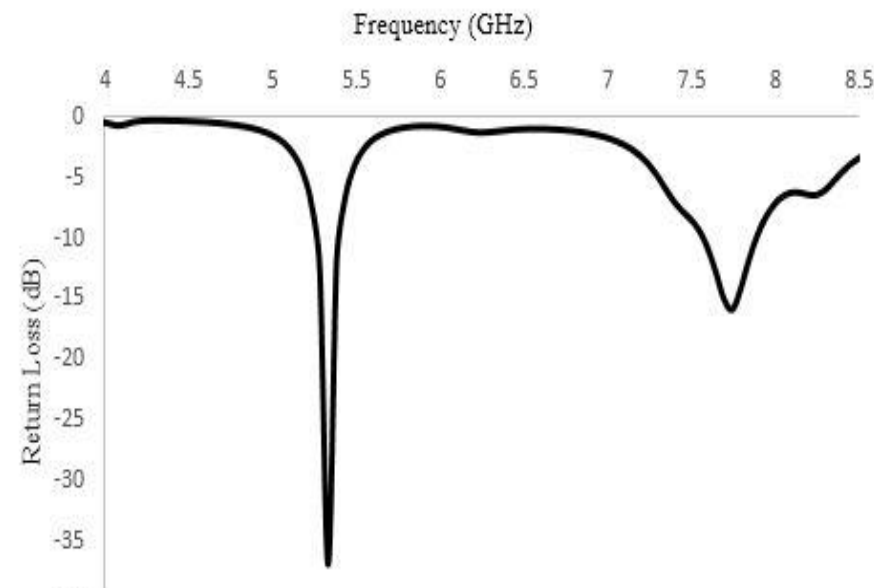

Fig-3 Return Loss of Patch 2 


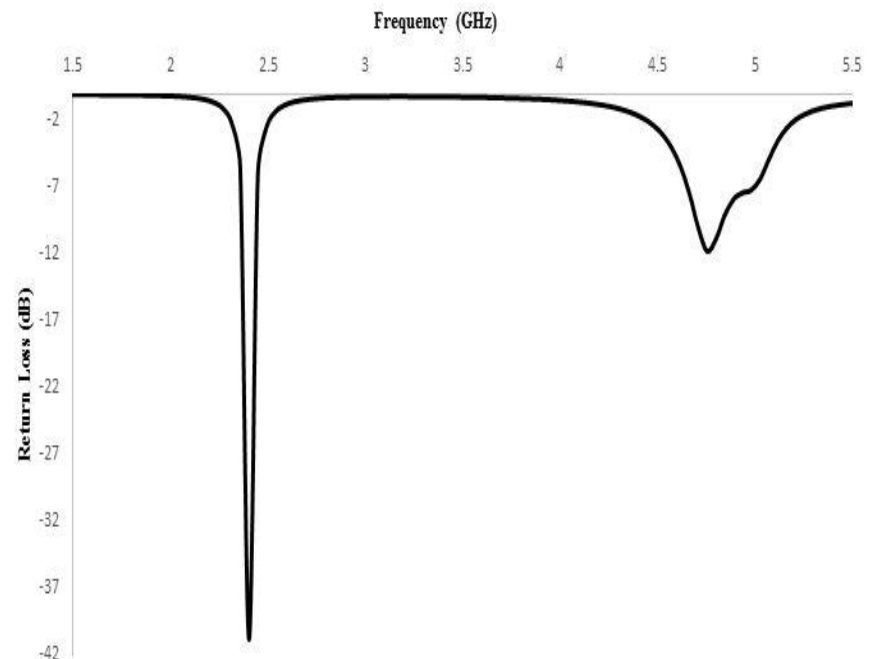

Fig-4 Return Loss of Patch 3

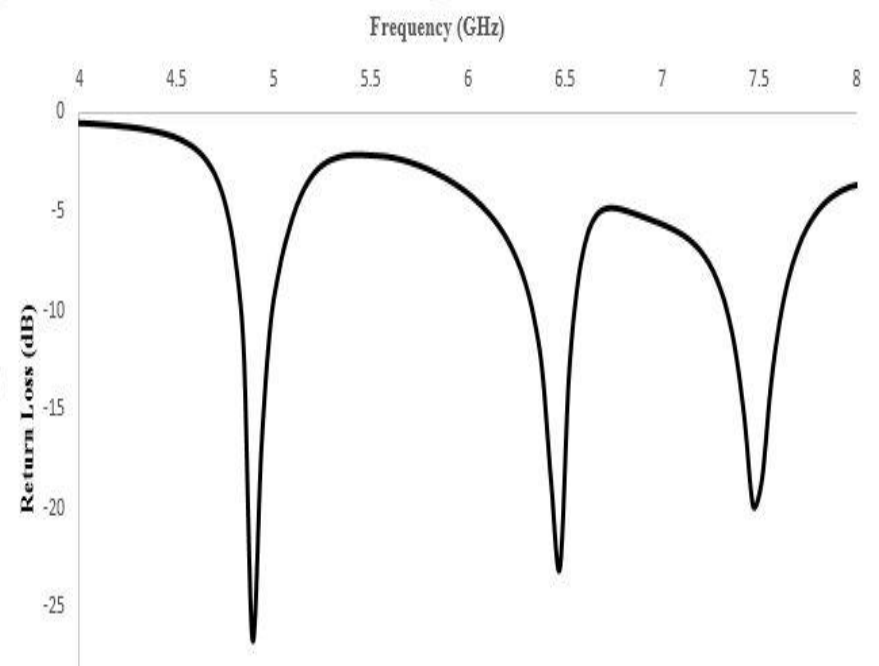

Fig-5 Return Loss of Patch 4

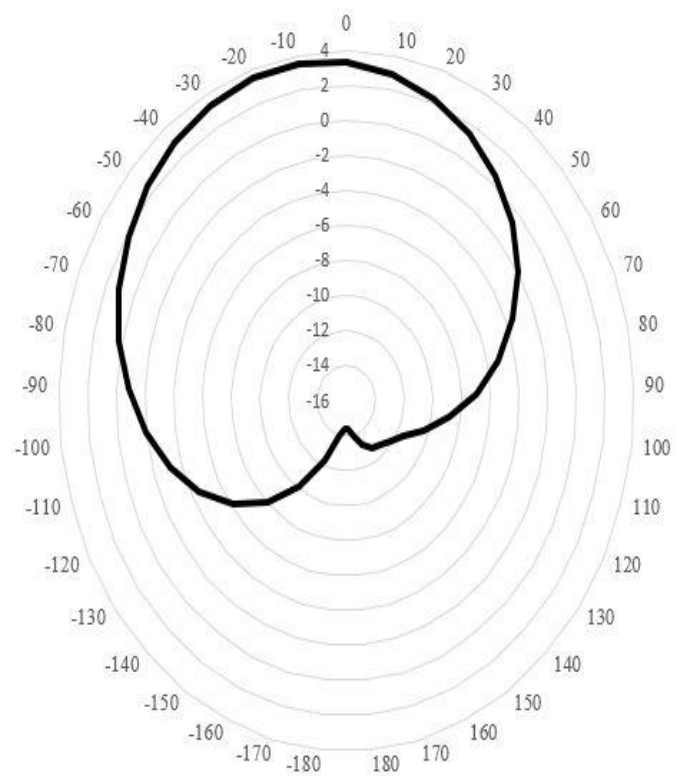

Fig-6 Radiation Pattern at $2.4 \mathrm{GHz}$

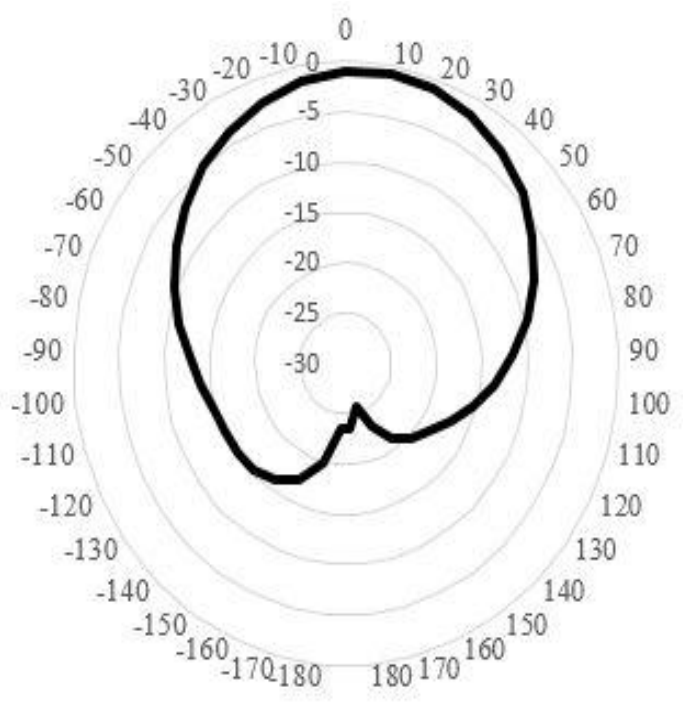

Fig-7 Radiation Pattern at $4.7 \mathrm{GHz}$

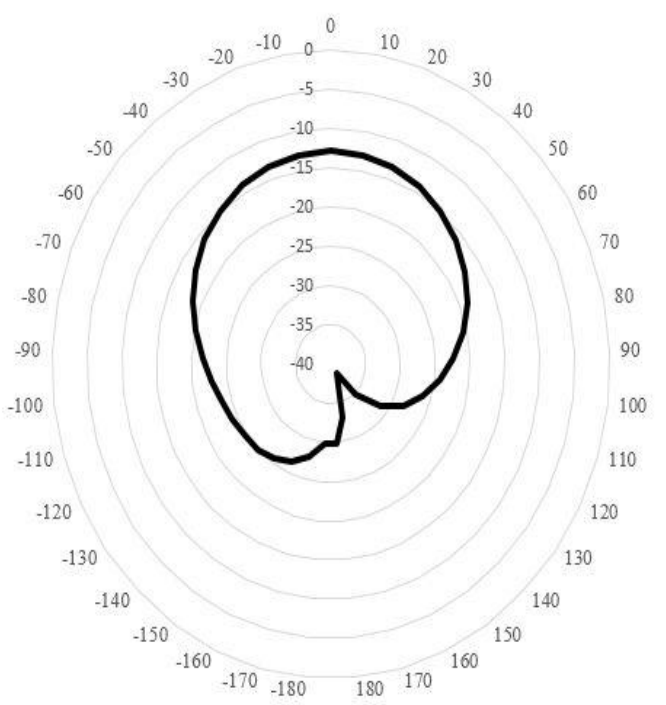

Fig-8 Radiation Pattern at $4.8 \mathrm{GHz}$

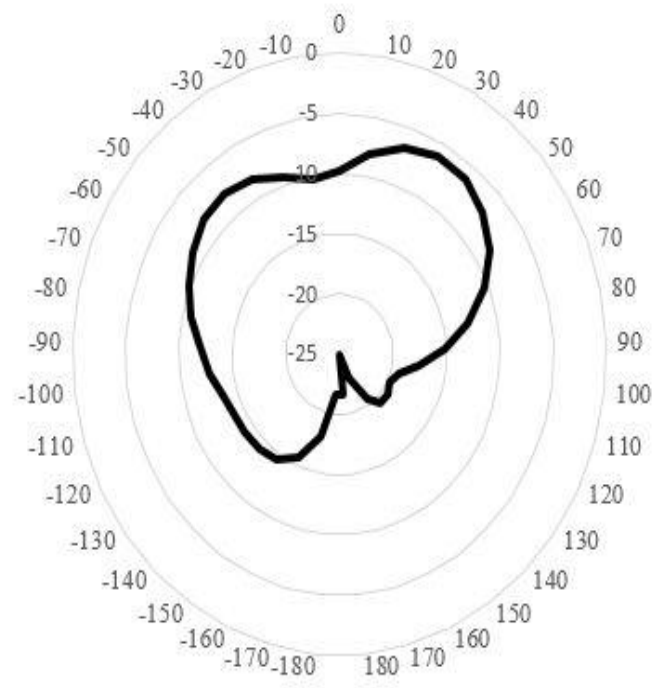

Fig-9 Radiation Pattern at $5.1 \mathrm{GHz}$ 


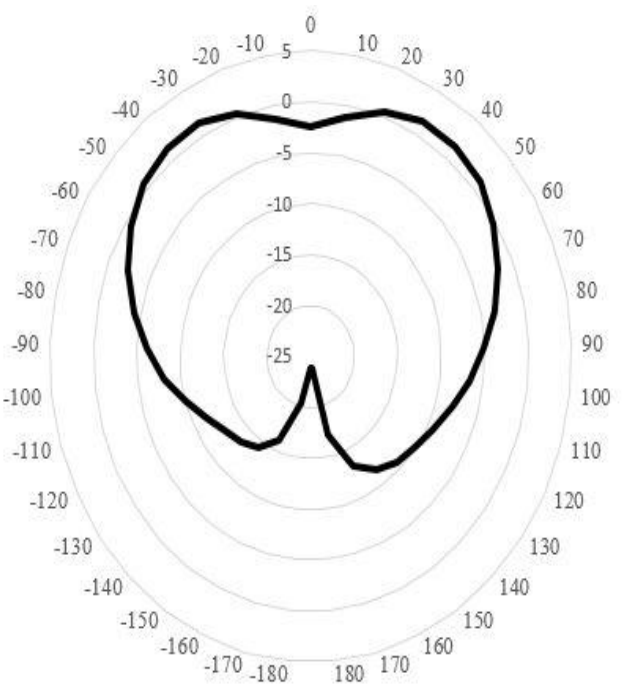

Fig-10 Radiation Pattern at $5.8 \mathrm{GHz}$

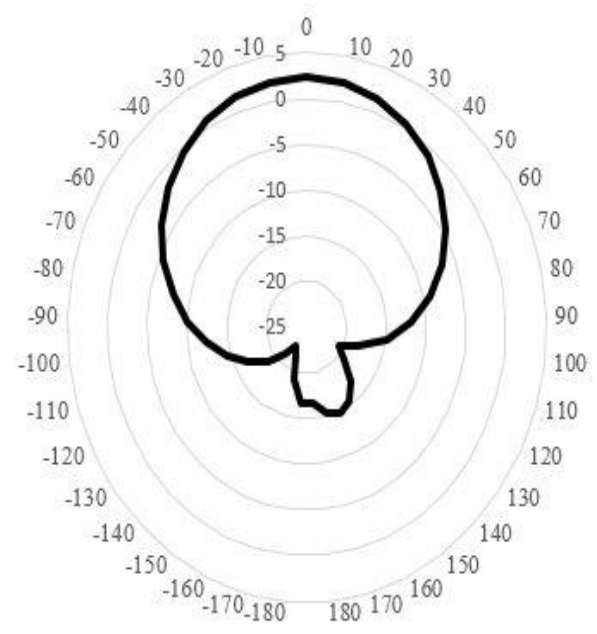

Fig-11 Radiation Pattern at $7.4 \mathrm{GHz}$

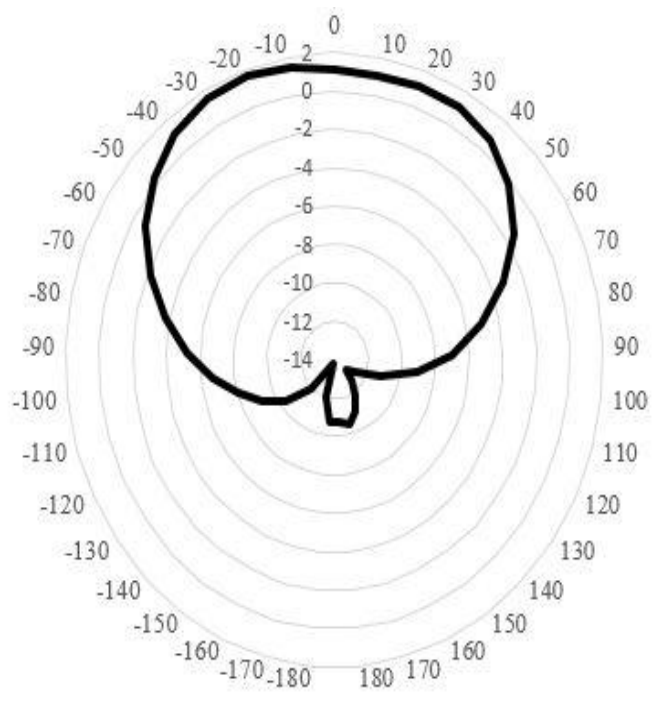

Fig-12 Radiation Pattern at 7.4 GHz
The radiation pattern at resonant frequencies are shown in Fig 6-12, calculated beam width is in the range of $80^{\circ}-90^{\circ}$.

The antenna simulated in HFFS 15.0 (high frequency structural simulator) and the performance is verified at $\mathrm{S}$ and $\mathrm{C}$ Band frequencies. The results show that the rectangular shaped structure can be used at multiple operating frequencies with extended lines.

\section{CONCLUSIONS}

In this paper, we have successfully exhibited a new conception of the rectangular antenna structure with two strip lines attached for $\mathrm{S}$ and $\mathrm{C}$ band frequencies. Finally, the proposed antenna has been simulated to perform the $\mathrm{Wi}$ MAX and WLAN applications.

\section{REFERENCES}

[1]. K. Gamage, M. Engjom, and I. A. Jensen, "Design of a low profile multi-band antenna for vehicular communication system," in Antennas and Propagation (EuCAP), 2013 7th European Conference on. IEEE, 2013, pp. 1273-1277.

[2]. N. Ojaroudi and N. Ghadimi, "UWB small slot antenna with wlan frequency band-stop function," Electronics Letters, vol. 49, no. 21, pp. 1317-1318, 2013.

[3]. M. Moosazadeh and S. Kharkovsky, "Compact and small patch antenna with symmetrical l-and u-shaped slots for wlan/wimax applications," 2014

[4]. O. P. Falade, M. U. Rehman, Y. Gao, X. Chen, and C. G. Parini, "Single feed stacked patch circular polarized antenna for triple band gps receivers," Antennas and Propagation, IEEE Transactions on, vol. 60, no. 10, pp. 4479-4484, 2012.

[5]. S. N. Sinha and M. Jain, "A self-affine fractal multiband antenna," Antennas and Wireless Propagation Letters, IEEE, vol. 6, pp. 110-112, 2007

[6]. N. Bayatmaku, P. Lotfi, M. Azarmanesh, and S. Soltani, "Design of simple multiband patch antenna for mobile communication applications using new eshape fractal," Antennas and Wireless Propagation Letters, IEEE, vol. 10, pp. 873-875, 2011

[7]. Kai-Fong Lee and Ahmed A. Kishk, "Dual- and Multiband U-Slot Patch Antennas", Antennas and Wireless Propagation Letters, IEEE, vol. 7, pp. 645648, 2008.

\section{BIOGRAPHIES}

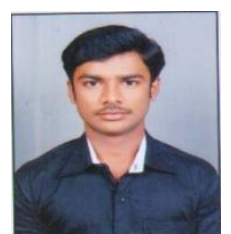

Pidugu Prasad, is presently pursuing his M.Tech. studies in the Department of Electronics and Communication Engg., National Institute of Technology, Warangal. He received his B.tech. Degree in Electronics \& Communication Engineering from Annamacharya Institute Of Technology and Sciences, JNTUA University, in 2011. His research area of interest includes antenna design, microwave circuits and RF circuits. 
Vakula. D obtained her Bachelor's degree in Electronics and Communication Engineering from Nagarjuna University, AP, India in 1992 and Master's degree from BIT Mesra India in 1994, with Microwave Engineering specialization. She obtained her doctoral degree on fault diagnosis of antenna arrays from National Institute of Technology, Warangal, India. Currently working as Assistant Professor at National Institute of Technology, Warangal, India. Her areas of interest include Microwave Engineering, Phased array antennas and Neural networks. She has published about 25 papers in various International and National Journals and Conferences. 